This item was submitted to Loughborough's Research Repository by the author.

Items in Figshare are protected by copyright, with all rights reserved, unless otherwise indicated.

\title{
A new NiCe complex derived from ortho-vanillin: Structural characterization and luminescence properties
}

PLEASE CITE THE PUBLISHED VERSION

https://doi.org/10.1016/j.molstruc.2018.08.047

\section{PUBLISHER}

(C) Elsevier

\section{VERSION}

AM (Accepted Manuscript)

\section{PUBLISHER STATEMENT}

This paper was accepted for publication in the journal Journal of Molecular Structure and the definitive published version is available at https://doi.org/10.1016/j.molstruc.2018.08.047.

\section{LICENCE}

CC BY-NC-ND 4.0

\section{REPOSITORY RECORD}

Kirpik, Hilal, Muhammet Kose, Mark Elsegood, and C.L. Carpenter-Warren. 2019. "A New Nice Complex Derived from Ortho-vanillin: Structural Characterization and Luminescence Properties". figshare. https://hdl.handle.net/2134/35173. 


\title{
A new NiCe complex derived from ortho-vanillin: Structural characterization and luminescence properties
}

\author{
Hilal Kırpık ${ }^{1}$, Mark R.J. Elsegood ${ }^{2}$, Cameron L. Carpenter-Warren ${ }^{2}$, Muhammet Kose ${ }^{1 *}$ \\ ${ }^{1}$ Chemistry Department, Kahramanmaras Sutcu Imam University, Kahramanmaras, 46050, \\ Turkey. \\ ${ }^{2}$ Chemistry Department, Loughborough University, Loughborough, LE11 3TU, UK.
}

\begin{abstract}
In this study, a new heteronuclear NiCe complex $\left[\mathrm{NiL}_{2} \mathrm{Ce}\left(\mathrm{NO}_{3}\right)_{2}(\mathrm{OAc})\left(\mathrm{H}_{2} \mathrm{O}\right)(\mathrm{X})\right] \cdot 1.25 \mathrm{H}_{2} \mathrm{O}$ (where $\mathrm{L}=$ ortovanillinato; $\mathrm{X}: \mathrm{H}_{2} \mathrm{O}$ or $\mathrm{CH}_{3} \mathrm{OH}$ ) was prepared and characterized by analytical and spectroscopic methods. Molecular structure of the complex was further characterised by single crystal X-ray diffraction study. In the structure of the complex, there are two geometrical isomers with only water as coordinated solvent at the $\mathrm{Ni}$ (II) centre, and two others with part water and part methanol at this site. In the structure of the complex, a $\mathrm{NiL}_{2}$ moiety is bound to the Ce(III) ion via two phenolic and two methoxy oxygen atoms of two ligands L. The coordination sphere of the Ce(III) ion is completed by the coordination of oxygen atoms of two bidentate nitrate anions, an acetate which bridges the two metal ions, and a water ligand. Hirshfeld surface analysis was performed to investigate the intermolecular contacts and their percentage contributions within the crystal packing. The complex molecules are linked by hydrogen bond contacts. The complex shows an emission band at 656 $\mathrm{nm}$ when excited at $317 \mathrm{~nm}$ with large stokes shift. The complex exhibits a reversible redox potential at $-0.36 \mathrm{~V}$ due to the cerium-based oxidation/reduction process.
\end{abstract}

Keywords: Ortho-vanillin; NiCe complex; X-ray structure; Emission spectra; Redox potential

Corresponding author: M. Kose

E-mail address: muhammetkose@ksu.edu.tr (Muhammet Kose) 


\section{Introduction}

The lanthanide complexes have wide range of applications in several areas including catalytic, resonance imaging, magnetic and fluorescent materials [1-5]. The magnetic properties of lanthanide complexes have received considerable attention and magnetic behaviours of those complexes can be tuned with ligand modifications [6]. For this purpose, several organic ligands have been used for the synthesis of lanthanide complexes with certain behaviours [7-9]. Due to interesting emission behaviors, trivalent lanthanide complexes have several advantages over organic base florescent molecules and nanoparticles. The main advatages of these compounds are well-defined line emission bands, high quantum yields and long lifetimes [10]. The Ln(III) ions shows low absorption coefficients from parity forbidden f-f transitions. The emission of $\operatorname{Ln}(\mathrm{III})$ ions is usually fulfilled by an indirect sensitization from chromophore ligands (antena effect) rather than direct excitation of the lanthanide centers $[11,12]$. Another indirect sensitization of $\operatorname{Ln}(\mathrm{III})$ is to introduce transition metal ions such as $\mathrm{Cr}(\mathrm{II}), \mathrm{Ru}(\mathrm{II}), \mathrm{Zn}(\mathrm{II})$ and $\mathrm{Cd}(\mathrm{II})$ [13-15].

Ortho-vanillin, also known as 3-methoxysalicylaldehyde, have ability to bind transtion metal ions through the phenolic, aldehydic and metoxy oxygen atoms [16-18]. In the transition metal complexes of ortho-vanillin, two ligands are usually coordinated to the metal in a trans arrangement [19]. Due to having relativity hard oxygen donor atoms, ortho-vanillin can also coordinate to the lanthanide ions $[\mathbf{2 0}, \mathbf{2 1}]$. A trinuclear Gd(III) complex of orthovanillin was synthesised and chracterised by X-ray crystallography [22]. Dy(III) complexes of ortho-vanillin were reported to show single-molecule magnet (SMM) behaviour [23]. The heteronuclear 3d-4f complexes show interesting magnetic and emission properties [24, 25]. The salen type multi-dentate ligands derived from ortho-vanillin are often used to prepare such heteronuclear 3d-4f complexes. The transition metal ions in those complexes binds to the $\mathrm{N}_{2} \mathrm{O}_{2}$ donor sets whiche the lanthanide ions coordinates to the outer methoxy and phenolic oxygen atoms $\left(\mathrm{O}_{2} \mathrm{O}_{2}\right)$ [26]

In our previous work, a $\mathrm{Ni}(\mathrm{II})-\mathrm{Ce}(\mathrm{III})$ heteronuclear complex derived from salen type ligand was prepared and its luminescence properties was investigated [27]. In this work, a new $\mathrm{Ni}(\mathrm{II})-\mathrm{Ce}(\mathrm{III})$ heteronuclear complex using ortho-vanillin as ligands was synthesised from one pot reaction. The complex was characterised by the spectroscopic and analytical techniques. Single crystals of the complex were obtained from $\mathrm{MeOH}$-diethylether diffusion and the structure of the new complex was studied by X-ray diffraction study. Finally, absorption and luminescent properties of the complex was investigated in detail. 


\section{Experimental}

\subsection{General methods}

Ortho-vanillin, $\mathrm{Ni}(\mathrm{OAc})_{2} \cdot 4 \mathrm{H}_{2} \mathrm{O}$ and $\mathrm{Ce}\left(\mathrm{NO}_{3}\right)_{3} \cdot 6 \mathrm{H}_{2} \mathrm{O}$ and solvents were purchased from commercial sources and used without further purification. The FT-IR spectrum was taken on a Perkin Elmer Paragon 1000 PC. CE-440 Elemental analyser was used for the elemental analysis of carbon, hydrogen and nitrogen. The absorption spectra were studied on a Shimadzu UV-1800 UV-Vis. spectrophotometer. The fluorescence spectra were collected on a Perkin Elmer LS55 luminescence spectrometer. The thermal analysis was carried out on a Perkin Elmer Pyris Diamond. The cyclic voltamograms at the glassy carbon electrode were obtained using a BAS 100W (Bioanalytical System, USA) electrochemical analyser.

\subsection{X-ray structures solution and refinement for the complex}

Data collection and cell refinement were performed using a Bruker D8 QUEST or Apex II diffractometer and data reduction was performed using Bruker SAINT [28]. Diffraction data were measured at 150(2) K using Mo-K $\alpha$ radiation. SHELX-2014/6 was used to solve and refine the structures [29-31]. The structure of the complex was solved by charge flipping method and refined on $F^{2}$ using all reflections [29-31] All the non-hydrogen atoms were refined using anisotropic atomic displacement parameters. $\mathrm{H}$ atoms bonded to oxygen atoms were located from difference maps and their positional and temperature factors were constrained. Further details of the crystal data and refinement are given in Table 1. The $\mathrm{H}$ atoms on the minor occupancy coordinated water sites could not be reliably located, so were not refined.

For the complex, there are four unique complex molecules and five water molecules of crystallisation in the asymmetric unit. Two of the metal complexes have the formula: [CeNi $\left.\left(\mathrm{C}_{8} \mathrm{H}_{7} \mathrm{O}_{3}\right)\left(\mathrm{NO}_{3}\right)_{2}\left(\mathrm{O}_{2} \mathrm{CCH}_{3}\right)\left(\mathrm{OH}_{2}\right)_{2}\right]$ with a fully occupied water ligand coordinated to the $\mathrm{Ni}$ ion; the other two have the formulae: [CeNi $\left(\mathrm{C}_{8} \mathrm{H}_{7} \mathrm{O}_{3}\right)\left(\mathrm{NO}_{3}\right)_{2}\left(\mathrm{O}_{2} \mathrm{CCH}_{3}\right)\left(\mathrm{OH}_{2}\right)_{\mathrm{x}}\left(\mathrm{CH}_{4} \mathrm{O}\right)_{\mathrm{y}}$ ] where $\mathrm{x}=1.47(2)$ and $\mathrm{y}=0.53(2)$ for one, and $\mathrm{x}=1.26(2)$ and $\mathrm{y}=0.74(2)$ for the other where the water coordinated to Ce is fully occupied, but that on $\mathrm{Ni}(\mathrm{II})$ is either water or methanol. 


\subsection{Synthesis of $\left[\mathrm{NiCe}(\mathrm{L})_{2}\left(\mathrm{NO}_{3}\right)_{2}(\mathrm{OAc})\left(\mathrm{H}_{2} \mathrm{O}\right)(\mathrm{X})\right] \cdot 1.25 \mathrm{H}_{2} \mathrm{O}$}

Ortho-vanillin (0.304 g, $2.00 \mathrm{mmol})$ and $\mathrm{Ni}(\mathrm{OAc})_{2} \cdot 4 \mathrm{H}_{2} \mathrm{O}(0.248 \mathrm{~g}, 1 \mathrm{mmol})$ was dissolved in methanol $(20 \mathrm{~mL})$ and refluxed for $2 \mathrm{~h}$. To the refluxing solution, $\mathrm{Ce}\left(\mathrm{NO}_{3}\right)_{3} \cdot 6 \mathrm{H}_{2} \mathrm{O}(0.43 \mathrm{~g}, 1 \mathrm{mmol})$ was added in $\mathrm{MeOH}(20 \mathrm{~mL})$ followed by addition of $\mathrm{NaOH}$ (0.08 g, $2 \mathrm{mmol}$ ). The clear green solution was refluxed for $24 \mathrm{~h}$ and cooled to room temperature. The solvent was removed on a rotary evaporator. The green colored product was washed with diethylether $(10 \mathrm{~mL})$ and dried in air. X-ray quality crystals were grown by $\mathrm{MeOH}$ - diethyl ether diffusion.

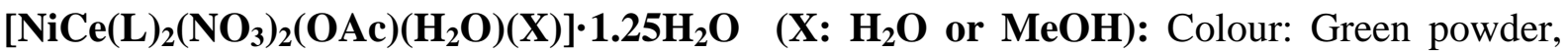
yield: $0.301 \mathrm{~g}$ (84\%). Elemental analyses for $\mathrm{C}_{18} \mathrm{H}_{21} \mathrm{~N}_{2} \mathrm{O}_{16} \mathrm{NiCe} \cdot 3 \mathrm{H}_{2} \mathrm{O} \cdot \mathrm{CH}_{3} \mathrm{OH}$ (MW: 806.26 g/mol): Calcld.: C, 28.30; H, 3.88; N, 3.47. Found: C, 28.12; H, 3.27; N, 3.12\%. IR (KBr, cm $\left.{ }^{1}\right)$ : 3405, 2945, 1620, 1572, 1492, 1351, 1245, 1182, 1087, 1032, 984, $960 \mathrm{~cm}^{-1}$.

\section{Results and Discussion}

In current study work, a new heterodinuclear NiCe complex was synthesised and characterized. The reaction of two equivalents of 2-hydroxy-3-methoxybenzaldehyde (HL) with one equivalent of $\mathrm{Ni}(\mathrm{OAc})_{2} \cdot 4 \mathrm{H}_{2} \mathrm{O}$ and $\mathrm{Ce}\left(\mathrm{NO}_{3}\right)_{3} \cdot 6 \mathrm{H}_{2} \mathrm{O}$ in the presence of two equivalents of $\mathrm{NaOH}$ gave a NiCe heteronuclear complex (Fig. 1). The green colored complex is soluble in methanol, ethanol, dimethylformamide and slightly soluble in water and not soluble in diethy ether. The FT-IR spectra of the complex was obtained to determine the characteristic stretching bands. The FT-IR spectrum of the complex shows a broad band at around $3400 \mathrm{~cm}^{-1}$ due to $v(\mathrm{O}-\mathrm{H})$ stretches of water or methanol molecules in the structure of the complex. In the FT-IR spectrum of the free HL ligand (ortho-vanillin), the carbonyl group stretching $v(\mathrm{C}=\mathrm{O})$ was seen at $1657 \mathrm{~cm}^{-1}$ [32] and upon coordination to the $\mathrm{Ni}(\mathrm{II})$ center, this stretch shifted to $1623 \mathrm{~cm}^{-1}$, confirming the coordination of the aldehyde oxygen atom to the metal centre. In the spectrum of the complex, the bands observed at 592 and $569 \mathrm{~cm}^{-1}$ were assigned to $v(\mathrm{M}-\mathrm{O})$ streches.

The thermal stability of the new hetero-dinuclear NiCe complex was studied under $\mathrm{N}_{2}$ atmosphere in the temperature range of $20-1000{ }^{\circ} \mathrm{C}$ with a heating rate of $10{ }^{\circ} \mathrm{C} / \mathrm{min}$ (see supplementary data). Thermal degradation of the complex under nitrogen atmosphere occurs in several steps. Thermal decomposition of the complex starts at about $50{ }^{\circ} \mathrm{C}$. In the range of $50-200{ }^{\circ} \mathrm{C}$, approximately $10 \%$ of the total mass was lost. This mass loss can be attributed to 
gradual loss of solvate water from the structure of the complex. The loss of solvate water by thermal decomposition is followed by two endothermic peaks at about 75 and $175{ }^{\circ} \mathrm{C}$. The molecular backbone of the complex started to decompose at about $200{ }^{\circ} \mathrm{C}$ and decomposes in five consecutive steps. In the first two decomposition steps $\left(200-305{ }^{\circ} \mathrm{C}\right.$ and $\left.305-410{ }^{\circ} \mathrm{C}\right)$, almost $45 \%$ of the total mass was lost and this loss was attributed to the removal of the coordinated external ligands $\left(\mathrm{CH}_{3} \mathrm{OH}, \mathrm{H}_{2} \mathrm{O}, \mathrm{AcO}^{-}\right.$and $\left.\mathrm{NO}_{3}{ }^{-}\right)$. The first two decomposition steps at $200-305{ }^{\circ} \mathrm{C}$ and $305-410{ }^{\circ} \mathrm{C}$ were followed by two exothermic peaks at 280 and 390 ${ }^{\circ} \mathrm{C}$, respectively. In the other decomposition steps, the rest of the organic moieties of the complex were lost gradually up to higher temperatures leaving metal oxides as the final residue. At $1000{ }^{\circ} \mathrm{C}$, almost $35 \%$ of the total mass remained and this corresponds to the metal oxides $\left(\mathrm{NiO}+\mathrm{CeO}_{2}\right)$.

\subsection{Molecular structure of $\left[\left(\mathrm{NiL}_{2}\right) \mathrm{Ce}\left(\mathrm{NO}_{3}\right)_{2}(\mathrm{OAc})\left(\mathrm{H}_{2} \mathrm{O}\right)(\mathrm{X})\right] \cdot 5 \mathrm{H}_{2} \mathrm{O}$}

The crystals of the complex have triclinic symmetry and the structure was solved in space group $P \overline{1}$. The asymmetric unit comprises four independent metal complexes plus five water molecules of crystallisation. There are two geometrical isomers with only water as coordinated solvent at the $\mathrm{Ni}$ (II) centre, and two others with part water and part methanol at this site. The asymmetric unit of the complex is shown in Fig. 2. In each independent complex molecule (prefixed with A-D in Fig. 2), the Ni(II) ion is six-coordinate binding to the two aldehyde and two phenolate oxygen atoms of two L ligands, one water or methanol oxygen and one acetate oxygen atom. The acetate ion and phenolate oxygen atoms bridge the Ni(II) and $\mathrm{Ce}(\mathrm{III})$ atoms. The Ce(III) ion in each complex molecule is ten-coordinate binding to the two phenolate, two methoxy, four oxygens of two nitrate ions, an acetate oxygen and a water oxygen atom.

Hirshfeld surface of the complex was generated to investigate the inter-molecular interactions in the structure $[32,33]$. The finger print plots and percentage contribution of different intermolecular contacts are given in Figs. 3\&4. Each molecule from the asymmetric unit stacks linearly along the $a$ axis. The molecules are held together via a complex network of hydrogen bonds between neighbouring molecules and bridging interactions involving the waters of crystallisation (Fig. 5). The $\mathrm{H} \cdots \mathrm{O} / \mathrm{O} \cdots \mathrm{H}$ hydrogen bon contacts plays an important role in crystal packing with $42.8 \%$ contribution. These contacts are shown as red spots in the $d_{n}$ surface. The fingerprint plot of the complex shows two spikes for $\mathrm{H} \cdots \mathrm{O} / \mathrm{O} \cdots \mathrm{H}$ contacts. The $\mathrm{H} \cdots \mathrm{H}$ and $\mathrm{C} \cdots \mathrm{H}$ contacts also stabilise the structure of the 
complex with $36.1 \%$ and $12.5 \%$ contributions, respectively. In the structure, phenyl rings show stacking interactions and $C \cdots C$ stacking contacts make $4.7 \%$ contribution to the overall stability of the complex.

Costes and co-workers have prepared several NiLn (Ln: Gd, Ce, Tb and Y) complexes derived from ortho-vanillin [34-36]. The treatment of complex [Ni(o-van $\left.)_{2}\left(\mathrm{H}_{2} \mathrm{O}\right)_{2}\right]$ with $\mathrm{Ln}\left(\mathrm{NO}_{3}\right)_{3} \cdot 6 \mathrm{H}_{2} \mathrm{O}$ gave heteronuclear NiLn complexes (where o-van is ortho-vanillin). The structures of the reported complexes were found to be solvent (used in the reaction) dependent [36]. In the $\mathrm{Ni}(\mathrm{II})$ complex of ortho-vanillin, two ligands are arranged in trans positions. Introduction of a Ln(III) ion leads the rearrangement of the ligands in a cis position to provide a binding site for a $\mathrm{Ln}(\mathrm{III})$ ion [34-36]. The reaction of $\left[\mathrm{Ni}(\mathrm{o}-\mathrm{van})_{2}\left(\mathrm{H}_{2} \mathrm{O}\right)_{2}\right]$ with $\mathrm{Ce}\left(\mathrm{NO}_{3}\right)_{3} \cdot 6 \mathrm{H}_{2} \mathrm{O}$ gave heterodinuclear $\mathrm{NiCe}$ complex with the formula of [Ni(0van $)_{2}\left(\mathrm{H}_{2} \mathrm{O}\right)_{2} \mathrm{Ce}\left(\mathrm{NO}_{3}\right)_{3}$ ] [36]. In the structure of the reported complex, each $\mathrm{Ni}(\mathrm{II})$ is sixcoordinated binding to the phenolate and aldehyde oxygen atoms of two ortho-vanillin ligands and two water molecules at the axial positions. The Ce(III) ions are ten-coordinate which binds to the bridging phenolate, methoxy oxygen atoms of the o-vanillin ligands and three chelating nitrato anions [36]. In the structure of the complex in this work, the acetate anion occupied one of the axial position which bridges $\mathrm{Ni}$ (II) and $\mathrm{Ce}(\mathrm{III})$ ions. The other axial position of $\mathrm{Ni}(\mathrm{II})$ ion is occupied by either $\mathrm{H}_{2} \mathrm{O}$ or $\mathrm{CH}_{3} \mathrm{OH}$.

\subsection{UV-Vis. and photoluminescence spectra of the complex}

The UV-Vis. absorption spectrum of the complex was studied in the 250-800 nm range in DMF $\left(10^{-5} \mathrm{M}\right)$. In the spectrum of the complex (Fig. 6), there is a broad absorption band at 335-435 nm range. The absorption band can be assigned to the $\pi$ - $\pi *$ electronic transitions due to the $\pi$-electrons in the phenyl ring. The emission and excitation spectra of complex are shown in Fig. 6. Upon excitation at 317 nm, complex exhibits only one emission band at $656 \mathrm{~nm}\left(\lambda_{\max }\right)$ with high emission intensity with stokes shift of $339 \mathrm{~nm}$. This emission band was assigned to the $\pi-\pi^{*}$ transition. The large stokes shift may due to the $\mathrm{M} \rightarrow \mathrm{L}$ and $\mathrm{L} \rightarrow \mathrm{M}$ charge transitions.

\subsection{Electrochemical studies}

Cyclic voltammograms (CV) of the complex was studied in DMF $\left(10^{-4} \mathrm{M}\right)$ using $0.1 \mathrm{M}$ $\mathrm{NBu}_{4} \mathrm{BF}_{4}$ as supporting electrolyte. The $\mathrm{CV}$ curves and electrochemical data are given in Fig 7\&Table 2. The complex shows one anodic peak potential at about $-0.36 \mathrm{~V}$ at all scan rates. At 250 scan rate $(\mathrm{mV} / \mathrm{s})$, the anodic peak potential is reversible and the metal based oxidation 
process is as follow: $\mathrm{Ce}(\mathrm{III}) \rightarrow \mathrm{Ce}(\mathrm{IV})+\mathrm{e}^{-}[37,38]$. The complex exhibited two cathodic peak potentials in the $-0.50-(+0.80) \mathrm{V}$ range. The cathodic peak potential observed in the $+0.67-$ $(+0.80) \mathrm{V}$ range is due to irreversible reduction of metal ions. While the anodic peak potentials (Epa) almost remain constant with the increase of the scan rate, the cathodic peak potentials $(E p c)$ shifted to more negative values.

\section{Conclusions}

A new hetero dinuclear NiCe complex derived from ortho-vanillin ligand was synthesized and characterized by spectroscopic and analytical methods. Molecular structure of the complex was determined by single crystal X-ray diffraction studies. In the structure of the complex, two ortho-vanillinato ligands coordinate to a $\mathrm{Ni}(\mathrm{II})$ and a $\mathrm{Ce}(\mathrm{III})$ through oxygen atoms. The molecules in the structure are linked by hydrogen bond contacts $(\mathrm{OH} \cdots \mathrm{O})$. The photoluminescence and electrochemical behaviors of the complex were studied in DMF solution. The complex gives an emission band at $656 \mathrm{~nm}\left(\lambda_{\text {exc }}: 317 \mathrm{~nm}\right)$ with large stokes shift. Thermal stability of the complex was studied under nitrogen atmosphere.

\section{Supplementary Information}

Crystallographic data have been deposited with the Cambridge Crystallographic Data Centre, CCDC number for the complex is 1842328. Copies of this information can be obtained from The Director, CCDC, 12 Union Road, Cambridge, CB2 1EZ, UK (fax: +44 1223 335033; email deposit@ccdc.cam.ac.uk or http://www.ccdc.cam.ac.uk). 


\section{References}

1] L.J. Xu, G.T. Xu, Z.N. Chen, Recent advances in lanthanide luminescence with metalorganic chromophores as sensitizers, Coord. Chem. Rev. 273-274 (2014) 47-62.

[2] S. V. Eliseeva, J.-C.G. Bünzli, Lanthanide luminescence for functional materials and biosciences, Chem. Soc. Rev. 39 (2010) 189-227.

[3] L. Charbonnière, R. Ziessel, M. Guardigli, A. Roda, N. Sabbatini, M. Cesario, Lanthanide tags for time-resolved luminescence microscopy displaying improved stability and optical properties, J. Am. Chem. Soc. 123 (2001) 2436-2437.

[4] R. Sessoli, A.K. Powell, Strategies towards single molecule magnets based on lanthanide ions, Coord. Chem. Rev. 253 (2009) 2328-2341

[5] J.C.G. Bünzli, Lanthanide luminescence for biomedical analyses and imaging, Chem. Rev. 110 (2010) 2729-2755.

[6] J.J. Baldoví, A. Gaita-Ariño, E. Coronado, Modeling the magnetic properties of lanthanide complexes: relationship of the REC parameters with Pauling electronegativity and coordination number, Dalt. Trans. 44 (2015) 12535-12538.

[7] B. Zhao, P. Cheng, Y. Dai, C. Cheng, D.Z. Liao, S.P. Yan, Z.H. Jiang, G.L. Wang, A nanotubular 3D coordination polymer based on a 3d-4f heterometallic assembly, Angew. Chem. Int. Ed. 42 (2003) 934-936.

[8] Z. Chen, B. Zhao, P. Cheng, X. Zhao, W. Shi, Y. Song, Communication A Purely Lanthanide-Based Complex Exhibiting Ferromagnetic Coupling and Slow Magnetic Relaxation Behavior A Purely Lanthanide-Based Complex Exhibiting Ferromagnetic Coupling and Slow Magnetic Relaxation Behavior, Inorg. Chem. 48 (2009) 3493-3495.

[9] X.Q. Zhao, B. Zhao, Y. Ma, W. Shi, P. Cheng, Z.H. Jiang, D.Z. Liao, S.P. Yan, Lanthanide(III)-cobalt(II) heterometallic coordination polymers with radical adsorption properties, Inorg. Chem. 46 (2007) 5832-5834.

[10] X.Q. Song, G.Q. Cheng, Y.A. Liu, Enhanced Tb(III) luminescence by d10transition metal coordination, Inorganica Chim. Acta. 450 (2016) 386-394.

[11] S.I. Klink, H. Keizer, F.C.J.M. Van Veggel, Transition metal complexes as photosensitizers for near-infrared lanthanide luminescence, Angew. Chem., Int. Ed. 39 (2000) 4319-4321.

[12] H. Maas, A. Currao, G. Calzaferri, Encapsulated lanthanides as luminescent materials, Angew. Chem. Int. Ed. 41 (2002) 2495-2497.

[13] L. Aboshyan-Sorgho, H. Nozary, A. Aebischer, J.C.G. Bünzli, P.Y. Morgantini, K.R. Kittilstved, A. Hauser, S. V. Eliseeva, S. Petoud, C. Piguet, Optimizing millisecond time scale near-infrared emission in polynuclear chrome(III)-lanthanide(III) complexes, J. Am. Chem. Soc. 134 (2012) 12675-12684. 
[14] P. Lian, H. Wei, C. Zheng, Y. Nie, J. Bian, Z. Bian, C. Huang, Synthesis, characteristics and photoluminescent properties of novel Ir-Eu heteronuclear complexes containing 2carboxyl-pyrimidine as a bridging ligand, Dalt. Trans. 40 (2011) 5476.

[15] S.K. Samanta, S.M.T. Abtab, P.S. Sardar, S. Sanyal, M. Chaudhury, S. Ghosh, Role of triplet states of two different ligands in the sensitized emission of $\mathrm{Ln}^{\mathrm{III}}\left(\mathrm{Eu}^{\mathrm{III}}, \mathrm{Tb}^{\mathrm{III}}\right)$ in $\mathrm{d}-\mathrm{f}$ hybrid tetranuclear heterometal $\left(\mathrm{Zn}^{\mathrm{II}}{ }_{2} \mathrm{Ln}^{\mathrm{II}}{ }_{2}, \mathrm{Cd}^{\mathrm{II}}{ }_{2} \mathrm{Ln}^{\mathrm{III}}{ }_{2}\right)$ complexes, Eur. J. Inorg. Chem. (2014) 3101-3113.

[16] M. Odabaşoğlu, F. Arslan, H. Ölmez, O. Büyükgüngör, Synthesis, crystal structures and spectral characterization of trans-bisaquabis(o-vanillinato)copper(II), cis-aquabis(ovanillinato)copper(II) and aqua[bis(o-vanillinato)-1,2-ethylenediimin]copper(II), Dye. Pigment. 75 (2007) 507-515.

[17] H. Guo and G. Zhao, Solid-State Synthesis and Characterization of a Copper ( II ) Complex with o -Vanillin, Asian J. Chem., 20 (2008) 2781-2784.

[18] Z.D. Lin and W. Zeng, Aquabis(2-formyl-6-methoxyphenolato)copper(II), Acta Crystallogr., Sect. E: Struct. Rep. Online 62 (2006) m1074-m1076.

[19] A. J. Mckinnon, T. N. Waters, and D. Halla, The colour isomerism and structure of copper co-ordination compounds. Part VII. The crystal of bissalicylaldehydatocopper (II), J. Chem. Soc., (1964) 3290-3294.

[20] J. Luzon, K. Bernot, I.J. Hewitt, C.E. Anson, A.K. Powell, R. Sessoli, Spin chirality in a molecular dysprosium triangle: The archetype of the noncollinear ising model, Phys. Rev. Lett. 100 (2008) 247205.

[21] L.F. Chibotaru, L. Ungur, A. Soncini, The origin of nonmagnetic kramers doublets in the ground state of dysprosium triangles: Evidence for a toroidal magnetic moment, Angew. Chem. Int. Ed. 47 (2008) 4126-4129.

[22] J.P. Costes, F. Dahan, F. Nicodème, A trinuclear gadolinium complex: Structure and magnetic properties, Inorg. Chem. 40 (2001) 5285-5287.

[23] J. Tang, I. Hewitt, N.T. Madhu, G. Chastanet, W. Wernsdorfer, C.E. Anson, C. Benelli, R. Sessoli, A.K. Powell, Dysprosium triangles showing single-molecule magnet behavior of thermally excited spin states, Angew. Chem. Int. Ed. 45 (2006) 1729-1733.

[24] J.-P. Costes, F. Dahan, A. Dupuis, J.-P. Laurent, A General Route to Strictly Dinuclear $\mathrm{Cu}(\mathrm{II}\}) / \mathrm{Ln}(\mathrm{II})$ Complexes. Structural Determination and Magnetic Behavior of Two Cu(II)/Gd(II) Complexes, Inorg. Chem. 36 (1997) 3429-3433.

[25] T. Kajiwara, M. Nakano, S. Takaishi, M. Yamashita, Coordination-tuned singlemolecule-magnet behavior of $\mathrm{Tb}^{\mathrm{III}}-\mathrm{Cu}^{\mathrm{II}}$ dinuclear systems, Inorg. Chem. 47 (2008) 86048606. 
[26] P. Chen, H. Chen, P. Yan, Y. Wang, G. Li, Effect of lanthanide contraction and rigid ligand on the structure of salen-type lanthanide complexes, Cryst. Eng. Comm. 13 (2011) 6237.

[27] S.A. Güngör, M. Kose, Synthesis, crystal structure, photoluminescence and electrochemical properties of a sandwiched Ni2Ce complex, J. Mol. Struct. 1150 (2017) 274278.

[28] (a) Bruker, APEX2 and SAINT, Bruker AXS Inc, Madison, Wisconsin, USA, 1998; (b) Bruker, SADABS, Bruker AXS Inc, Madison, Wisconsin, USA, 2009.

[29] G.M. Sheldrick, A short history of SHELX, Acta Crystallogr. Sect. A Found. Crystallogr. 64 (2008) 112-122.

[30] G.M. Sheldrick, Crystal structure refinement with SHELXL, Acta Crystallogr. Sect. C Struct. Chem. 71 (2015) 3-8.

[31] G.M. Sheldrick, SHELXT - Integrated space-group and crystal-structure determination, Acta Crystallogr. Sect. A Found. Crystallogr. 71 (2015) 3-8.

[32] M.A. Spackman, D. Jayatilaka, Hirshfeld surface analysis, Cryst. Eng. Comm. 11 (2009) 19-32.

[33] J. Bernstein, R.E. Davis, L. Shimoni, N. -L Chang, Patterns in Hydrogen Bonding: Functionality and Graph Set Analysis in Crystals, Angew. Chemie Int. Ed. English. 34 (1995) 1555-1573.

[34] J.-P. Costes, L. Vendier, Structural and Magnetic Studies of New NiII-LnIII Complexes, Eur. J. Inorg. Chem. 2010 (2010) 2768-2773.

[35] J.-P. Costes, L. Vendier, W. Wernsdorfer, Structural and magnetic studies of original tetranuclear CoII-LnIII complexes (LnIII = Gd, Tb, Y), Dalt. Trans. 40 (2011) 1700.

[36] J.-P. Costes, F. Dahan, L. Vendier, S. Shova, G. Lorusso, M. Evangelisti, Ni II _Ln III complexes with o -vanillin as the main ligand: syntheses, structures, magnetic and magnetocaloric properties, Dalt. Trans. 47 (2018) 1106-1116.

[37] C. Chen, H. Chen, P. Yan, G. Hou, G. Li, Structure and electrochemistry of salen type cerium (IV) complexes tuned by multiform counterions, Inorganica Chim. Acta. 405 (2013) 182-187.

[38] P.Y. Jiang, Y. Ikeda, M. Kumagai, Electrochemical study on Ce(III) nitrate complex with n-Octyl(phenyl)-N, N-diisobutyl-carbamoylmethylphosphine oxide in acetonitrile, J. Nucl. Sci. Technol. 31 (1994) 491-493. 